\title{
Contact Lens Correction of Regular and Irregular Astigmatism
}

\author{
Raul Martín Herranz, Guadalupe Rodríguez Zarzuelo \\ and Victoria de Juan Herráez \\ University of Valladolid, School of Optometry, Optometry Unit - IOBA Eye Institute \\ Spain
}

\section{Introduction}

An astigmatism is an ametropia in which light rays do not focus at a single point (American Academy Ophthalmology, 2005) but form two focal lines. This image of a point is called a conoid of Sturm with two main focal or two primary meridians (Michaels D, 1988). If the primary meridians are always $90^{\circ}$ apart, then it is a regular astigmatism. An irregular astigmatism occurs when the primary meridians are not perpendicular.

Astigmatisms can be classified as regular or irregular based on the contribution of the ocular component and by orientation (Benjamin W, 1998). Clinically, one of the most common criteria employed is with respect to the refractive error (i.e., myopia and hyperopia).

- Compound myopic astigmatism: both focal lines lie in front of the retina.

- Simple myopic astigmatism: one focal line is anterior to the retina, while the other one coincides with the retina (it is in focus).

- Compound hyperopic astigmatism: both focal lines lie behind the retina.

- Simple hyperopic astigmatism: one focal line is behind the retina, and the other one coincides with the retina (it is in focus).

- Mixed astigmatism: one focal line lies in front of and the other behind the retina.

In the correction of the refractive errors, spectacles should be considered before contact lenses or refractive surgery (American Academy Ophthalmology, 2005). However, in some astigmatism cases, contact lenses will be the choice method, especially in cases with irregular astigmatisms. The astigmatism compensation with spectacle lenses is possible if the primary meridians are perpendicular because ophthalmic astigmatic lenses can only correct orthogonal astigmatisms. An irregular astigmatism is difficult to correct with standard spectacles, and subjects often complain of blurring (due to the loss of the corrected visual acuity), monocular diplopia or poliopia. In these cases, obliquely crossed cylinders and other techniques have been proposed (Benjamin W, 1998), although visual acuity reached with this method could be inferior to the best possible treatment. This outcome represents an important problem in patients with induced irregular astigmatisms related to a primary eye disease or secondary to some eye surgical procedure or traumatism.

Regular astigmatisms can be corrected with standard ophthalmic lenses, contact lenses and surgical procedures. However, irregular astigmatisms are more difficult to correct with glasses because the visual acuity could be lower than expected. Contact lens could be an 
elective way to improve visual acuity in these cases. Different surgical procedures have been proposed to correct irregular astigmatism.

In this chapter, we explore ways to correct regular and irregular astigmatism with contact lenses to improve visual function as compared with the visual acuity obtained with a standard ophthalmic spectacle lenses correction.

\section{Regular and irregular astigmatism}

The cornea is the main refringent surface of the eye. It represents the largest change in the refractive index, and a small change in the corneal radius induces a large effect on power. For this reason, astigmatisms are most frequently produced by the toricity of the anterior corneal surface (Benjamin W, 1998).

The toricity of the lens surfaces or tilting of the lens can be responsible for an astigmatism, and this is referred to as lenticular astigmatism. However, the magnitude of a lenticular astigmatism is small and frequently in the direction opposite that of a corneal astigmatism (Benjamin W, 1998). The abnormal location of the fovea with respect to the optic axes could be also responsible of astigmatism. Lens and retina-induced astigmatisms are called internal astigmatism. Clinically, the most important astigmatisms are attributable to the cornea surface.

For this reason, astigmatisms are clinically classified based on the perpendicularity of the principal meridians of the cornea in regular and irregular corneas.

The clinical assessment of the cornea with keratometry and corneal topography is described in previous chapters of this book. A keratometer is one of the most commonly used instruments for corneal curvature measurements. Corneal topography has been a powerful advance in corneal assessment and permits full corneal exploration. The main disadvantages of corneal topography systems include errors in alignment, focusing, calibration and soft and hardware data interpretation (Hom M, 2000).

Corneal topography is very useful in corneal assessments to classify corneal astigmatisms. Although the different corneal topography devices are available, all of them generate a color-coded topographical map of the corneal curvature (Figure 1). In general, hot colors (red) are used to represent steeper points of the cornea (with high power and low corneal radius), and cold colors (blue) are used to represent the flatter regions of the cornea (with low power and high corneal radius). In a regular astigmatism, the corneal topography is similar to a tie with two perpendicular main meridians (Figure 1-A). In an irregular astigmatism, the corneal topography does not have the two perpendicular meridians (Figure 1-B).

\subsection{Regular astigmatism}

In regular astigmatisms, the meridians having the maximum and minimum refractive power are separated by a $90^{\circ}$ angle. In these cases, the main meridians of the cornea are perpendicular, and the main focus lines must be orthogonal (Figure 1-A).

Regular astigmatisms may be classified as either with-the-rule or against-the-rule astigmatisms. In with-the-rule astigmatisms, the vertical meridian is the steepest. This type is the more common regular astigmatism, especially in children. In against-the-rule astigmatisms, the horizontal meridian is steeper than vertical one, and this is more frequent found in older adults. The term oblique astigmatism is used to describe a regular astigmatism in which the orientation of the main meridians is not $90^{\circ}$ and $180^{\circ}$ (American Academy Ophthalmology, 2005). 


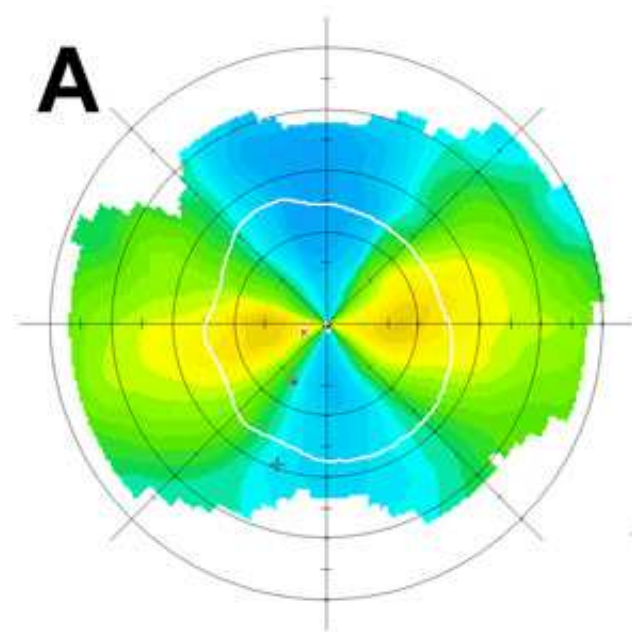

\section{Regular Astigmatism}

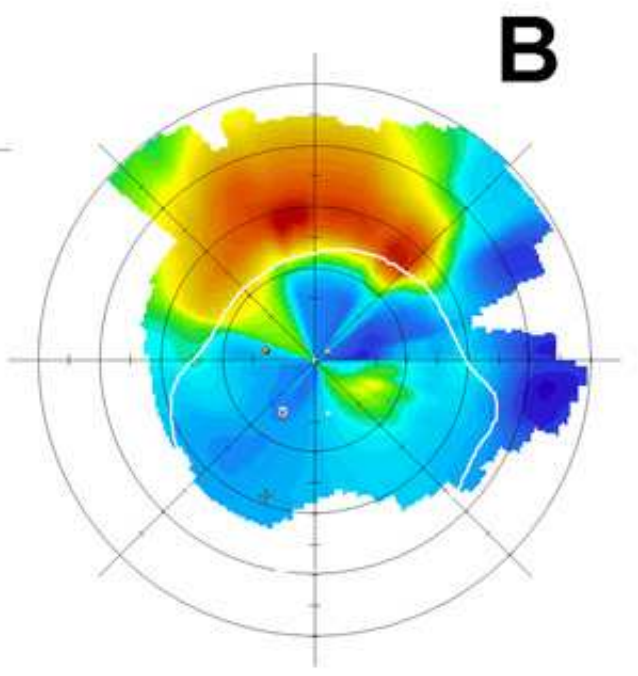

\section{Irregular Astigmatism}

Fig. 1. Corneal topographies in regular and irregular astigmatisms. A: Regular astigmatism of 4.0 diopters with two perpendicular main meridians. B: Irregular astigmatism of 6.5 diopters with non-perpendicular main meridians.

\subsection{Irregular astigmatism}

In irregular astigmatisms, the meridians having the maximum and minimum refractive power are separated by an angle other than $90^{\circ}$. In these cases, the principal meridians are not perpendicular to one another. Furthermore, an irregular astigmatism is defined when the orientation of the principal meridians or the amount of astigmatism changes from point to point across the eye pupil (American Academy Ophthalmology, 2005). For this reason, irregular astigmatism is often used to describe patients with irregular corneal surfaces (Figure 1-B). Importantly, all eyes have at least a small amount of irregular astigmatism (American Academy Ophthalmology, 2005) when the entire corneal surface is assessed, but this is not relevant from a clinical point of view. Significant irregular astigmatism is uncommon and could be related to scarred cornea, keratoconus and surgical procedures.

\section{Contact lens}

A contact lens is a thin plastic or glass lens that is fitted over the cornea to correct various vision defects (American Heritage Dictionary, 2011). Contact lenses are an adequate device to correct refractive errors (American Academy Ophthalmology, 2005), and there are 125 
millions of contact lenses wearers in the world. Contact lens compensation of an astigmatism requires the correct selection of the contact lens design for each case (Figure 2). Refractive astigmatism is the sum of the corneal astigmatism and the lenticular astigmatism, so astigmatism correction with contact lenses must consider both types of ocular astigmatisms. This consideration is important in cases in which the disparity between the corneal and refractive astigmatism suggests an important amount of lenticular astigmatism. For example, if a rigid gas permeable (RGP) contact lens is fitted (see below) in a case with a

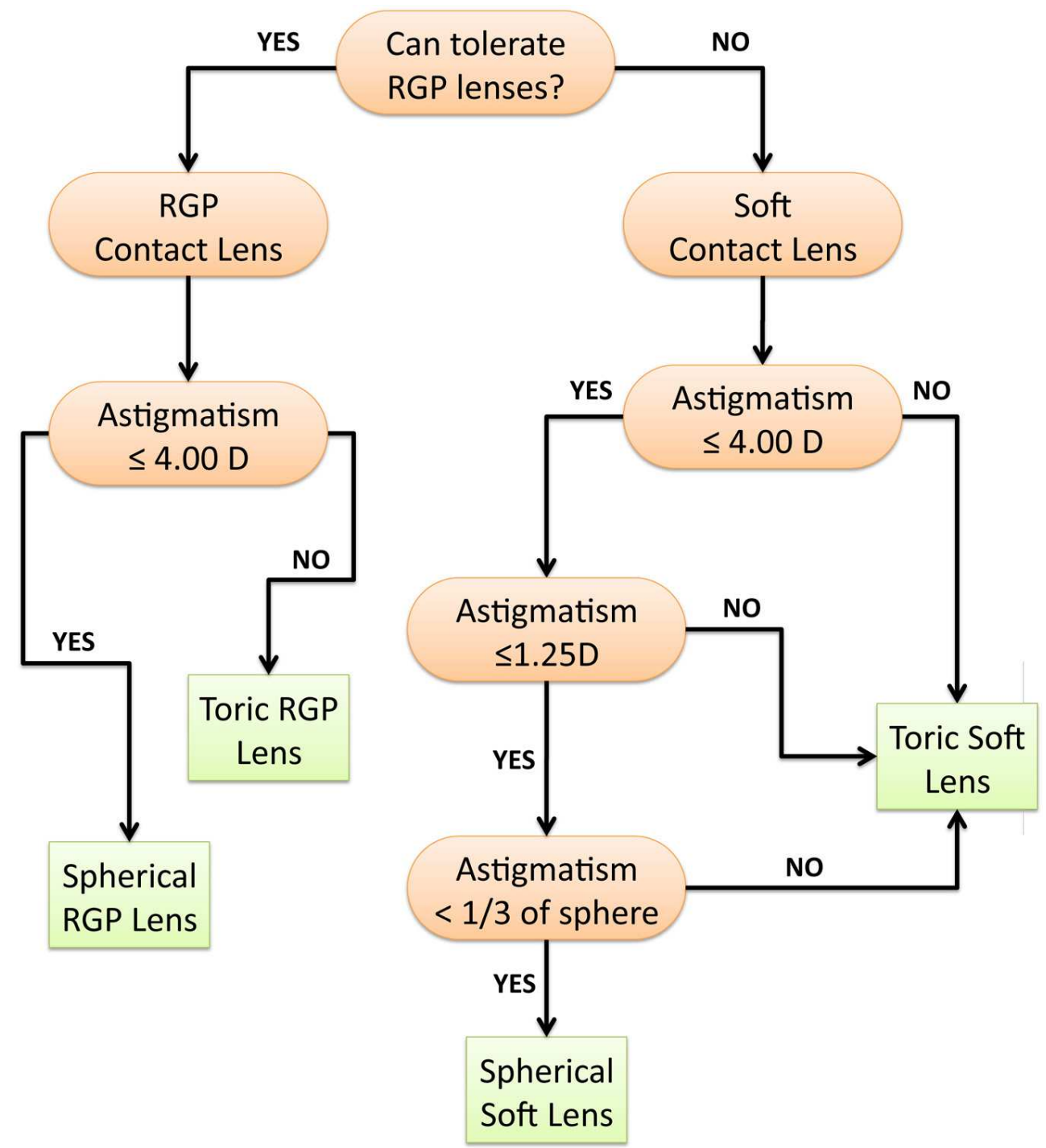

Fig. 2. General guidelines for contact lens fitting in patients with astigmatism (adapted from Key JE, 1998). RGP: Rigid gas permeable. 
higher refractive astigmatism than corneal astigmatism, an important amount of residual astigmatism (related to lenticular astigmatism) could affect the visual acuity. In these cases, a toric design of RGP contact lens or a toric soft contact lens could be suitable.

Contact lens designs have been approved with different lens replacement frequencies (i.e., daily, monthly, frequent replacement) and with different types of wear: daily wear (contact lenses are worn during open-eye time) and extended or continuous wear (contact lenses are worn during sleep and time spent awake). When considering a contact lens to correct an astigmatism, the type of contact lens must be chosen (Table 1). To prevent contact lens rotation with patient blinking, different systems are provided, such as adding a prism ballast (adding extra material in the inferior zone of the lens), truncating or removing the bottom of the lens or creating thin zones (on the top or in the bottom of the lens). Soft toric lenses often incorporate either a prism ballast or thin zones (Figure 3), but RGP toric lenses stabilize better with a back toric surface. RGP front toric lenses also need a stabilization system.

\begin{tabular}{|l|l|}
\hline Amount of Astigmatism & First Choice of Lens \\
\hline$<1.00 \mathrm{D}$ & Spherical soft or RGP \\
\hline 1.00 to $4.00 \mathrm{D}$ & Toric soft lens or spherical RGP \\
\hline$>4.00 \mathrm{D}$ & Toric RGP or custom soft toric lens \\
\hline
\end{tabular}

Table 1. General rule for contact lens choice based on the amount of refractive astigmatism. RGP: Rigid gas permeable.

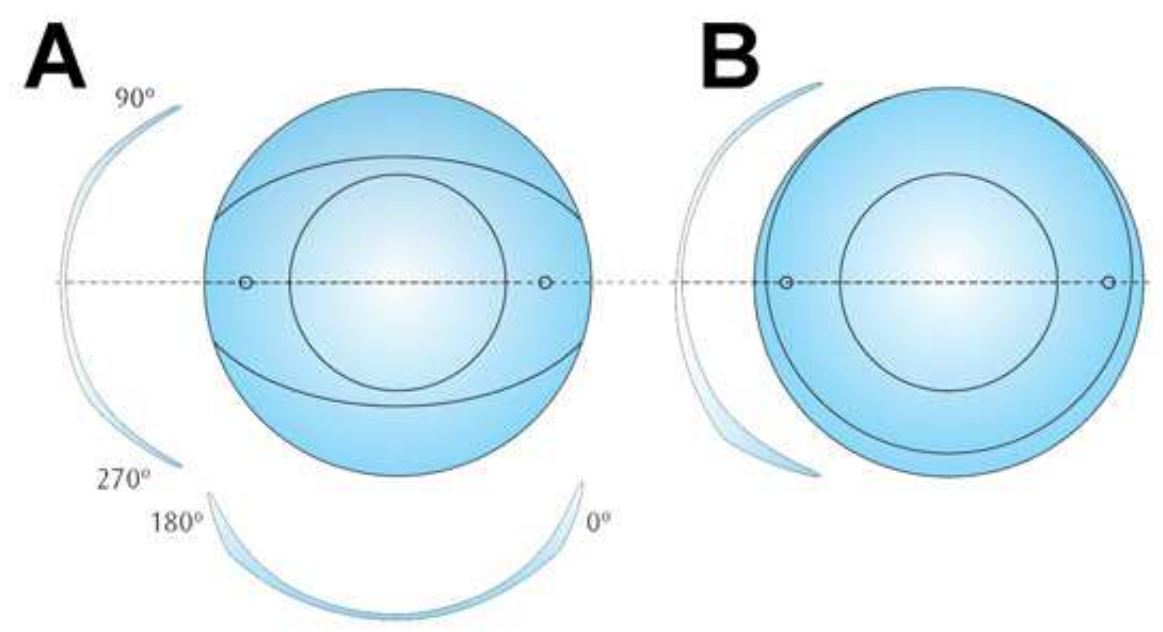

Fig. 3. Soft toric contact lens design. A. Dynamic toric stabilization system used in toric soft contact lens design. This design permits the correction of astigmatisms lower than $8.00 \mathrm{D}$. B. Prismatic stabilization system located in the inferior contact lens area. Courtesy of Hecht Contactlinsen/Conoptica. 


\subsection{Soft contact lenses}

Soft contact lenses are made of a flexible plastic material, which is normally hydrophilic. These lenses are generally more comfortable than rigid contact lens, and the lens diameter is large, extending beyond the sclerocorneal limbus. When a soft lens is placed on the eye, the lens conforms to the anterior corneal shape, and the refractive effect of the tears between the contact lens and the cornea is minimized.

Soft contact lens must be fabricated with different power in the main meridians to correct the astigmatism. The manufacturing process permits several toric contact lenses with different power, but they always use perpendicular principal meridians to correct regular astigmatisms. For this reason, soft contact lenses are not an adequate option to correct irregular astigmatisms.

\subsection{Rigid gas permeable contact lenses}

An RGP contact lens is constructed of a rigid plastic that transmits oxygen to the cornea. RGP lenses have a diameter lower than the corneal diameter. The refractive effects of contact lenses when they are placed on the eye depend largely on whether those lenses conform to the corneal topography. RGP contact lenses do not conform to the corneal shape, and the contact lens-cornea interface produces a post-lens tear pool with refractive power because they are not parallel surfaces (anterior corneal surface and posterior contact lens radius). The post-lens tear film is called a lacrimal lens, tear lens or fluid lens (Benjamin W, 1998). The power of the tear lens is determined by the difference in curvature between the cornea and the posterior radius of the contact lens.

Because the refractive index of tears is similar to the refractive index of the cornea, the tear lens or the lacrimal lens can neutralize more than $90 \%$ of the regular and irregular corneal astigmatism. The tear lens is an additional lens in which the anterior curvature radius is determined by the back RGP lens radius, and the posterior radius coincides with the anterior corneal curvature. Therefore, the difference in the power of the steepest and flattest corneal meridians is neutralized by the tear lens, and this simplifies the contact lens power calculation on astigmatic corneas. Additionally, this power effect must be considered in the RGP contact lens spherical power calculation. For example, an RGP back surface steeper than the corneal curvature (apical clearance) will produce a tear lens with positive power, and a RGP back surface parallel to the corneal curvature (apical alignment) will produce a tear lens with no power (plano-parallel film). For an RGP back surface that is flatter than the corneal curvature (apical bearing), the power will be negative (like a divergent lens).

The refractive effect of the tear lens would be of paramount importance in regular and irregular astigmatism correction with RGP contact lens (Figure 4).

RGP contact lenses could be manufactured with different powers in the principal meridians with two different posterior radii. Clinically, a regular astigmatism lower than $4.00 \mathrm{D}$ can be corrected with the refractive effect of the tear lens fitting a spherical RGP contact lens. However, the lens could be instable or could flex and affect subject comfort or visual acuity in some cases. For such cases and in higher regular astigmatisms, a toric RGP contact lens could be fitted to improve subject comfort and visual acuity. The exact RGP contact lens fitting technique is not the objective of this chapter.

\section{Regular astigmatism correction with contact lenses}

A regular astigmatism is easy to correct with contact lenses, although some points must be considered. With an astigmatism lower than $1 / 3$ of the sphere refractive error, a spherical 


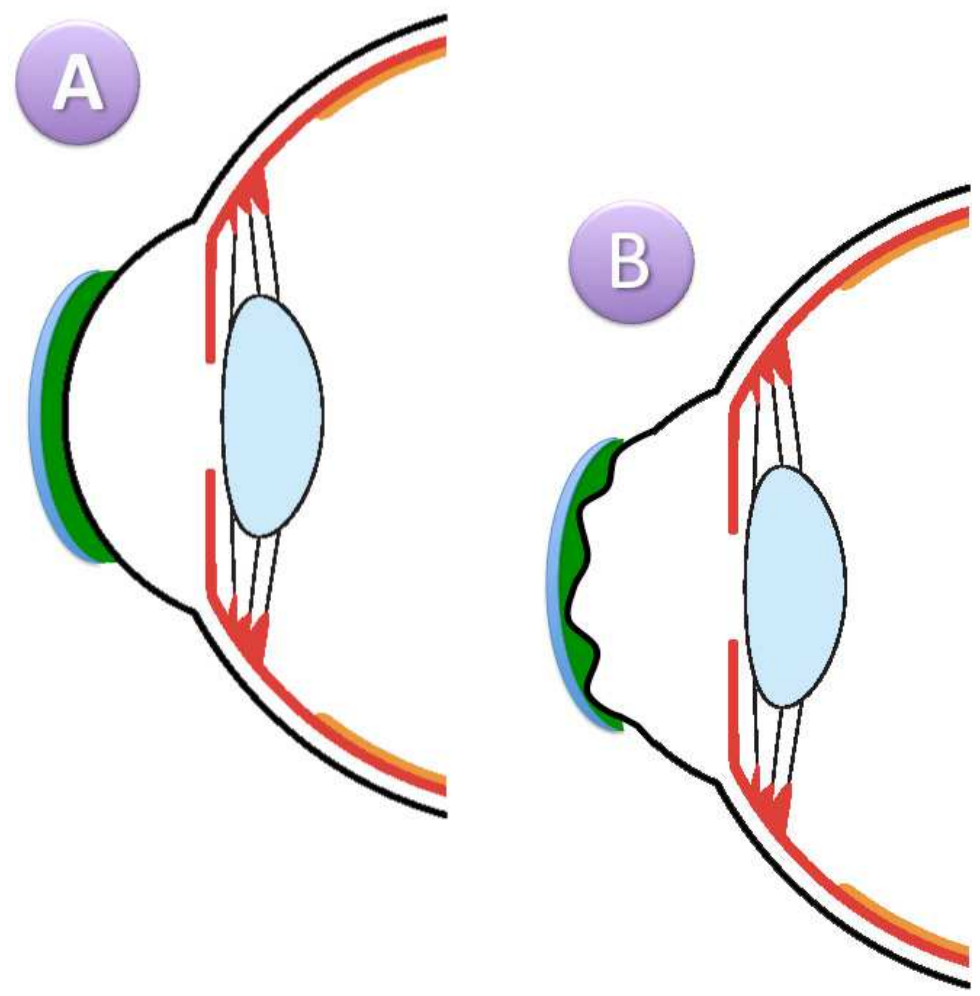

Fig. 4. A schematic representation of the lacrimal lens or tear lens in RGP contact lens fitting. The tear lens is represented in green (like the exploration with fluorescein in clinical practice). A. In regular astigmatisms, the tears between the lens and the cornea correct the astigmatism. The tear lens power is determined by the difference in curvature between the cornea and base curve of the contact lens, including the spherical and toric power. B. In irregular astigmatisms (with irregular anterior corneal surface), the tear film completes the space between the contact lens and cornea and homogenizes the irregular surface.

contact lens may be the first option, both soft or RGP. With spherical soft contact lens, where visual acuity could be incorrect, a soft toric or spherical RGP lens must be fitted.

Contact lens visual acuity depends of the type of lens chosen. In general, visual acuity in patients with astigmatisms will be better with RGP lenses than with soft contact lenses. We present four cases to illustrate regular astigmatism corrections with soft toric, spherical and toric RGP contact lenses and five cases of irregular astigmatism correction with RGP contact lenses.

\subsection{Soft contact lens correction}

A 31-year-old female patient was fitted with contact lenses for the first time. The patient wanted to participate in sports while wearing the contact lenses. Visual acuity, refraction and keratometry are shown in Table 2, and the slit lamp examination was within the normal limits. Corneal topography revealed a regular astigmatism of $2.00 \mathrm{D}$ approximately. 


\begin{tabular}{|c|c|c|c|c|}
\hline $\begin{array}{c}\text { Visual } \\
\text { acuity }\end{array}$ & $\begin{array}{c}\text { Subjective } \\
\text { refraction }\end{array}$ & DCVA & Manual keratometry & VA with CL \\
\hline 0.10 & $-4.25-1.50 \times 5^{\circ}$ & 1.0 & $\begin{array}{c}7.90 \mathrm{~mm} @ 180^{\circ} / \\
7.50 \mathrm{~mm} @ 90^{\circ}\end{array}$ & 1.0 \\
\hline
\end{tabular}

Table 2. Visual acuities before and after contact lens fitting and manual keratometry. VA: visual acuity, DCVA: Distance corrected visual acuity, CL: Contact Lens.

Toric silicon hydrogel contact lenses were proposed because the patient presented a medium to moderate astigmatism. RGP contact lenses were not recommended because the patient wanted to practice sports in which the contact lenses could be lost. The lens parameters are shown in Table 3.

\begin{tabular}{|c|c|c|c|c|l|}
\hline Radius & $\phi \mathrm{T}$ & Power & $\begin{array}{c}\text { Design/ } \\
\text { Model }\end{array}$ & Material & Manufacturer \\
\hline $8.70 \mathrm{~mm}$ & $14.00 \mathrm{~mm}$ & $-4.25-1.50 \times 5^{\circ}$ & $\begin{array}{c}\text { Purevision } \\
\text { Toric }\end{array}$ & $\begin{array}{c}\text { Balafilcon } \\
\text { A }\end{array}$ & Bausch\&Lomb \\
\hline
\end{tabular}

Table 3. The lens parameters. $\phi \mathrm{T}$ : total diameter.

This contact lens design (balanced vertical thickness profile and prism ballasting geometry) uses the natural force of the lids to orient and center the lens during and between blinks. In addition, the lens has integrated aspheric optics to reduce the amount of positive spherical aberration of the eye and to help improve retinal image quality in low-light conditions (Young G, 2003). Contact lens examination revealed good movement and tear exchange without complications. The contact lenses showed good centration with the stabilization marks in the correct position (Figure 5).

\subsection{Rigid gas permeable contact lens correction}

RGP contact lenses could be a useful option to correct regular astigmatisms and provide a high visual acuity. Lens design could be defined with general rules (Figure 2) according to the patient's astigmatism. For low astigmatisms, a spherical RGP may be recommended (Case 2), but with high astigmatisms, a toric RGP lens could be necessary (Case 3). Toric RGP lenses are also necessary to correct lens astigmatism (Case 4).

\subsubsection{Case 2: Spherical RGP lens to correct low astigmatism}

A 34-year-old female RGP contact lenses wearer ( 8 - 10 hours per day) refers good tolerance and vision acuity but wants new contact lenses because of the poor condition of her current ones.

\begin{tabular}{|c|c|c|c|c|}
\hline $\begin{array}{c}\text { Visual } \\
\text { acuity }\end{array}$ & $\begin{array}{c}\text { Subjective } \\
\text { refraction }\end{array}$ & DCVA & $\begin{array}{c}\text { Manual } \\
\text { keratometry }\end{array}$ & VA with CL \\
\hline 0.05 & $+7.00\left(-2.00 \times 130^{\circ}\right)$ & 0.4 & $\begin{array}{r}8.06 \mathrm{~mm} @ 150^{\circ} / \\
7.62 \mathrm{~mm} @ 60^{\circ}\end{array}$ & 0.4 \\
\hline
\end{tabular}

Table 4. Visual acuities before and after contact lens fitting and manual keratometry. VA: visual acuity, DCVA: Distance corrected visual acuity, CL: Contact Lens. 

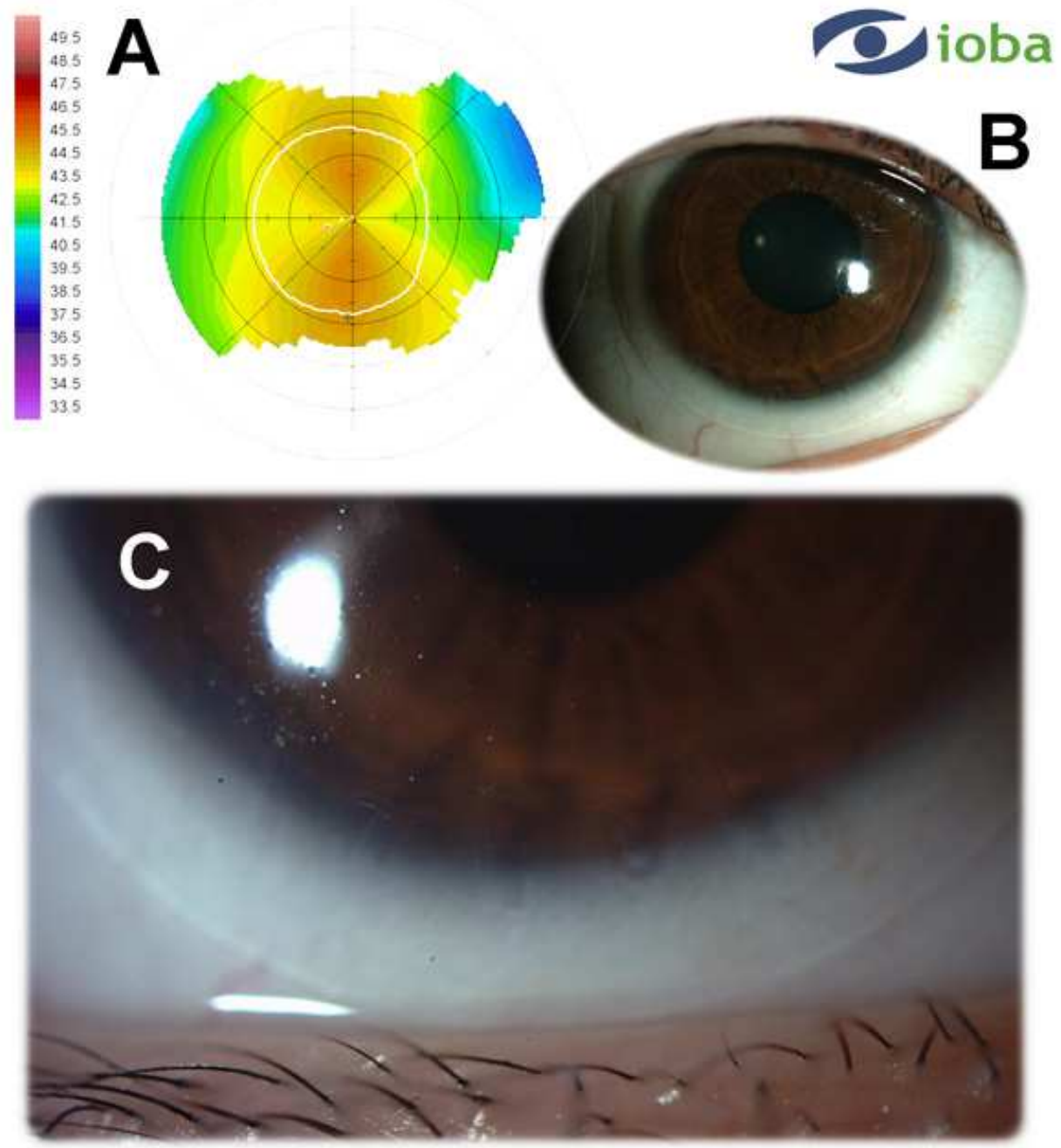

Fig. 5. Summary of Case 1. A. Detail of the corneal topography of $2.00 \mathrm{D}$ regular with-therule astigmatism. B. Soft contact lens with scleral position. C. Detail of the soft contact lens stabilization marks in the correct position (at five, six and seven o'clock).

The refractive parameters are shown in Table 4. This case present a mild amblyopia related with high compound hyperopic astigmatism. Corneal topography (Figure 6-A) shows a mild corneal astigmatism pattern, which is similar to a refractive astigmatism.

An RGP lens with an aspheric design was selected. With this type of geometry, the corneal astigmatism is corrected with the toroidal tear lens that is formed between the contact lens and cornea (Meyler J.G., 1994). Because there is a mild astigmatism (i.e., the difference between the principal meridians of the cornea is small), an aspheric lens that is stable and without excessive movement is possible. 
Table 5 shows the parameters of the final lens. The base curve was selected, in agreement with the nomogram provided by manufacturer, and it is slightly steeper than $\mathrm{K}$ on the basis of manual keratometry. Figure 6-B shows the fluorescein pattern in which one meridian has a low amount of fluorescein (corresponding to flattest meridian of the cornea) and another meridian has more fluorescein in peripheral area (corresponding to the steepest meridian of the cornea). The patient showed good tolerance.

For mild refractive astigmatisms, which correspond with corneal astigmatisms, RGP aspheric lens provides a suitable correction with good stability and tolerance.

\begin{tabular}{|c|c|c|c|c|c|}
\hline Radius & $\phi \mathbf{T}$ & Power & $\begin{array}{c}\text { Design/ } \\
\text { Model }\end{array}$ & Material & Manufacturer \\
\hline $8.00 \mathrm{~mm}$ & $9.60 \mathrm{~mm}$ & +7.75 & BIAS-S & Boston ES & $\begin{array}{c}\text { Hecht } \\
\text { Contactlinsen / } \\
\text { Conoptica }\end{array}$ \\
\hline
\end{tabular}

Table 5. Lens parameters. $\phi$ T: total diameter.

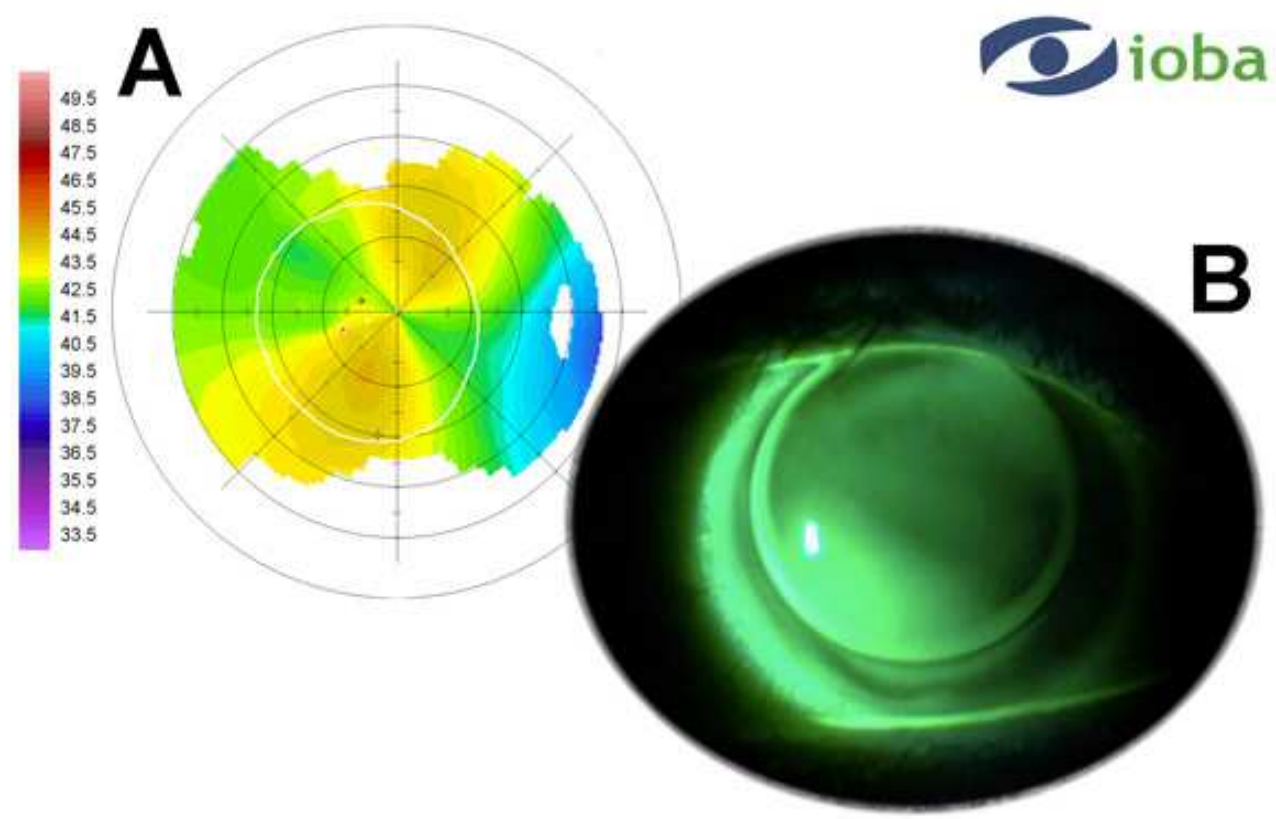

Fig. 6. Summary of Case 2. A. Detail of the corneal topography with an astigmatism of about 2.50 D. B. Fluorescein pattern with aspheric RGP lens that showed a central alignment and good edge clearance in the astigmatic axes.

\subsubsection{Case 3: Toric RGP lens to correct moderate astigmatism}

A 42-year-old female was fitted with contact lenses for the first time. She had worn spectacles since childhood. Visual acuity, refraction and keratometry are shown in Table 6, 
and the slit lamp examination was within normal limits. Corneal topography (keratograph topography) revealed a regular astigmatism of approximately $2.00 \mathrm{D}$ (Figure 7-A).

\begin{tabular}{|c|c|c|c|c|}
\hline $\begin{array}{c}\text { Visual } \\
\text { acuity }\end{array}$ & $\begin{array}{c}\text { Subjective } \\
\text { refraction }\end{array}$ & DCVA & Manual keratometry & VA with CL \\
\hline Not taken & $-3.50-3.00 \times 130^{\circ}$ & 0.9 & $\begin{array}{c}8.25 \mathrm{~mm} @ 180^{\circ} / \\
7.60 \mathrm{~mm} @ 90^{\circ}\end{array}$ & 0.9 \\
\hline
\end{tabular}

Table 6. Visual acuities before and after contact lens fitting and manual keratometry. VA: visual acuity, DCVA: Distance corrected visual acuity, CL: Contact Lens.

A bitoric RGP contact lens was proposed because the patient presented a moderate astigmatism and a residual astigmatism. With lenses incorporating a toroidal back surface, rotation is generally not a problem due to the stabilizing effect of the toric back surface on the toric cornea (Efron N, 2002). The lens parameters are shown in Table 7. Examination revealed good movement and centering. The central area displayed good alignment with optimal clearance under the peripheral curve and the edge lift permitted tear exchange (Figure 7-B).

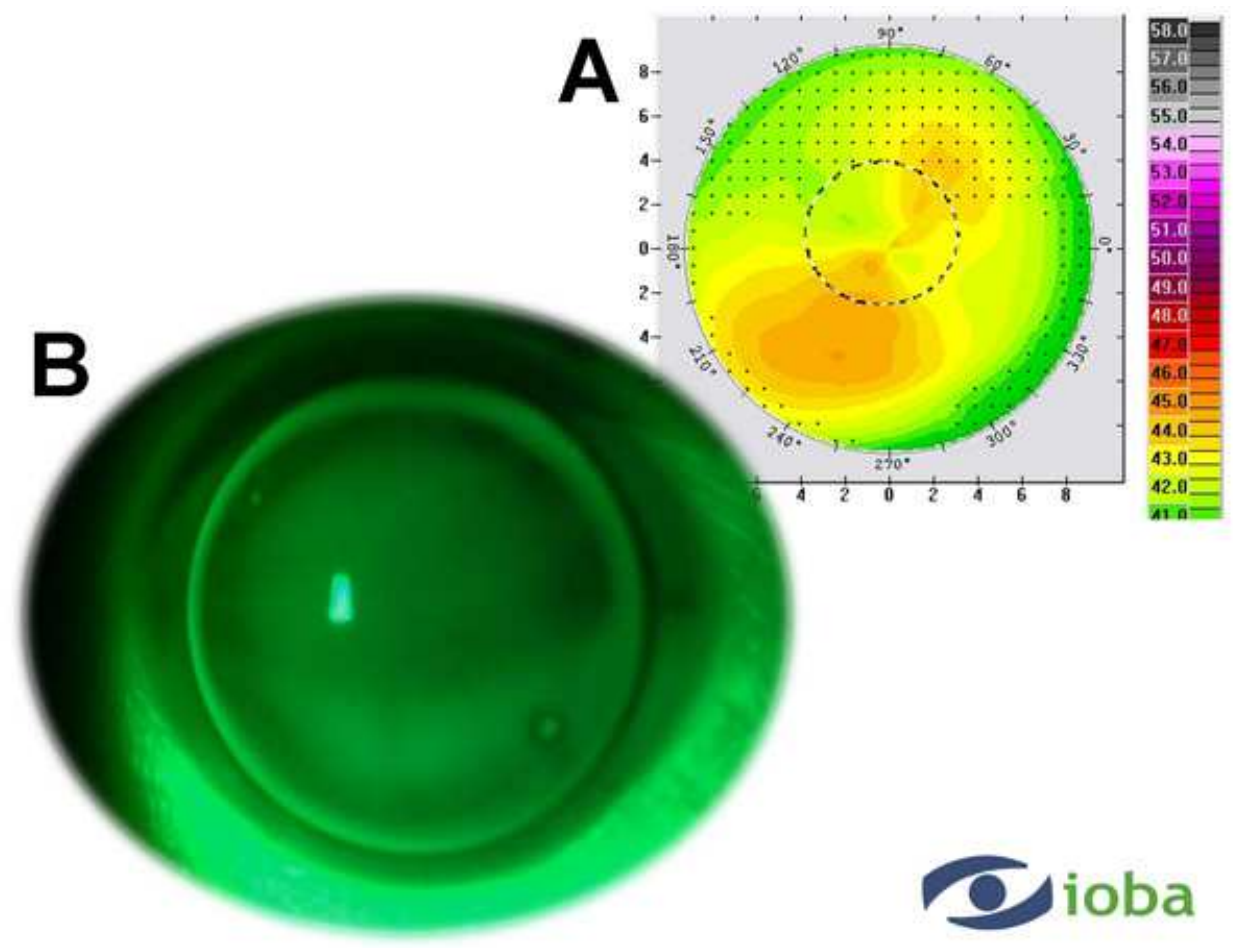

Fig. 7. Summary of Case 3. A. Keratograph topography showed a regular astigmatism. B. Fluorescein pattern with bitoric RGP lens showed central alignment and good edge clearance. The CL marks are aligned with the flattest corneal meridian. 


\begin{tabular}{|c|c|c|c|c|c|}
\hline Radius & $\phi \mathbf{T}$ & Power & $\begin{array}{c}\text { Design/ } \\
\text { Model }\end{array}$ & Material & Manufacturer \\
\hline $7.90 \mathrm{~mm}$ & $9.60 \mathrm{~mm}$ & $-4.00 \mathrm{D}$ & $\begin{array}{c}\text { Bitoric/BIAS } \\
\text { MAC }\end{array}$ & Boston ES & $\begin{array}{c}\text { Hecht } \\
\text { Contactlinsen / } \\
\text { Conoptica }\end{array}$ \\
\hline
\end{tabular}

Table 7. The lens parameters. $\phi$ T: Total diameter.

\subsubsection{Case 4: Toric RGP lens to correct lens astigmatism}

Case 4 is a 38-year-old female with congenital and bilateral subluxation of the lens due to Marfan's syndrome (a genetic disorder of the connective tissue). The refractive data are summarized in Table 8. The patient wore soft toric contact lens with low water content for about 12 hours per day during last 24 years with good tolerance. Due to hypoxic stimuli maintenance during this time, corneal neovascularization can be observed in both eyes (Efron N, 2004) (Figure 8-A). The patient expressed the need to improve the visual acuity (VA) of her current contact lenses to obtain a driver's license.

RGP contact lenses provide better quality of vision in high ametropias and supply more oxygen permeability than conventional soft contact lens (Ichijima $\mathrm{H}$ and Cavanagh HD, 2007). For these two reasons, RGP lens was selected. In this case, the cornea is practically spherical (Figure 8-B), and all of the astigmatism is internal.

\begin{tabular}{|c|c|c|c|c|}
\hline VA & $\begin{array}{c}\text { Subjective } \\
\text { refraction }\end{array}$ & DCVA & Manual keratometry & VA with CL \\
\hline$<0.05$ & $-25.00\left(-5.00 \times 115^{\circ}\right)$ & 0.6 & $\begin{array}{c}7.80 \mathrm{~mm} @ 15^{\circ} / \\
7.60 \mathrm{~mm} \mathrm{@} 105^{\circ}\end{array}$ & 0.8 \\
\hline
\end{tabular}

Table 8. Visual acuities before and after contact lens fitting and manual keratometry. VA: visual acuity, DCVA: Distance corrected visual acuity, CL: Contact Lens.

To obtain parallelism between the contact lens and the cornea, the internal surface of the contact lens must be spherical (or aspherical), and the correction of the astigmatism must be performed with a toric design on the external surface of the contact lens. Because contact lenses with internal spherical (or aspherical) surfaces tend to rotate constantly over the cornea with blinking, a stabilization system is necessary to maintain the lens in the correct position. A ballast prism is one of the most used systems.

Table 9 shows the parameters of the final lens. The base curve was selected in agreement with the nomogram provided by the manufacturer. The fluorogram showed parallelism

\begin{tabular}{|c|c|c|c|c|c|}
\hline Radius & $\phi \mathbf{T}$ & Power & $\begin{array}{c}\text { Design/ } \\
\text { Model }\end{array}$ & Material & Manufacturer \\
\hline $8.00 \mathrm{~mm}$ & $9.40 \mathrm{~mm}$ & $-21.00-5.25 \times 90^{\circ}$ & BIAS VPT & $\begin{array}{c}\text { Boston } \\
\text { XO }\end{array}$ & $\begin{array}{c}\text { Hecht } \\
\text { Contactlinsen / } \\
\text { Conoptica }\end{array}$ \\
\hline
\end{tabular}

Table 9. The lens parameters. $\phi \mathrm{T}$ : Total diameter. The lens included a prism of $1.5 \Delta$ to facilitate lens stabilization. 


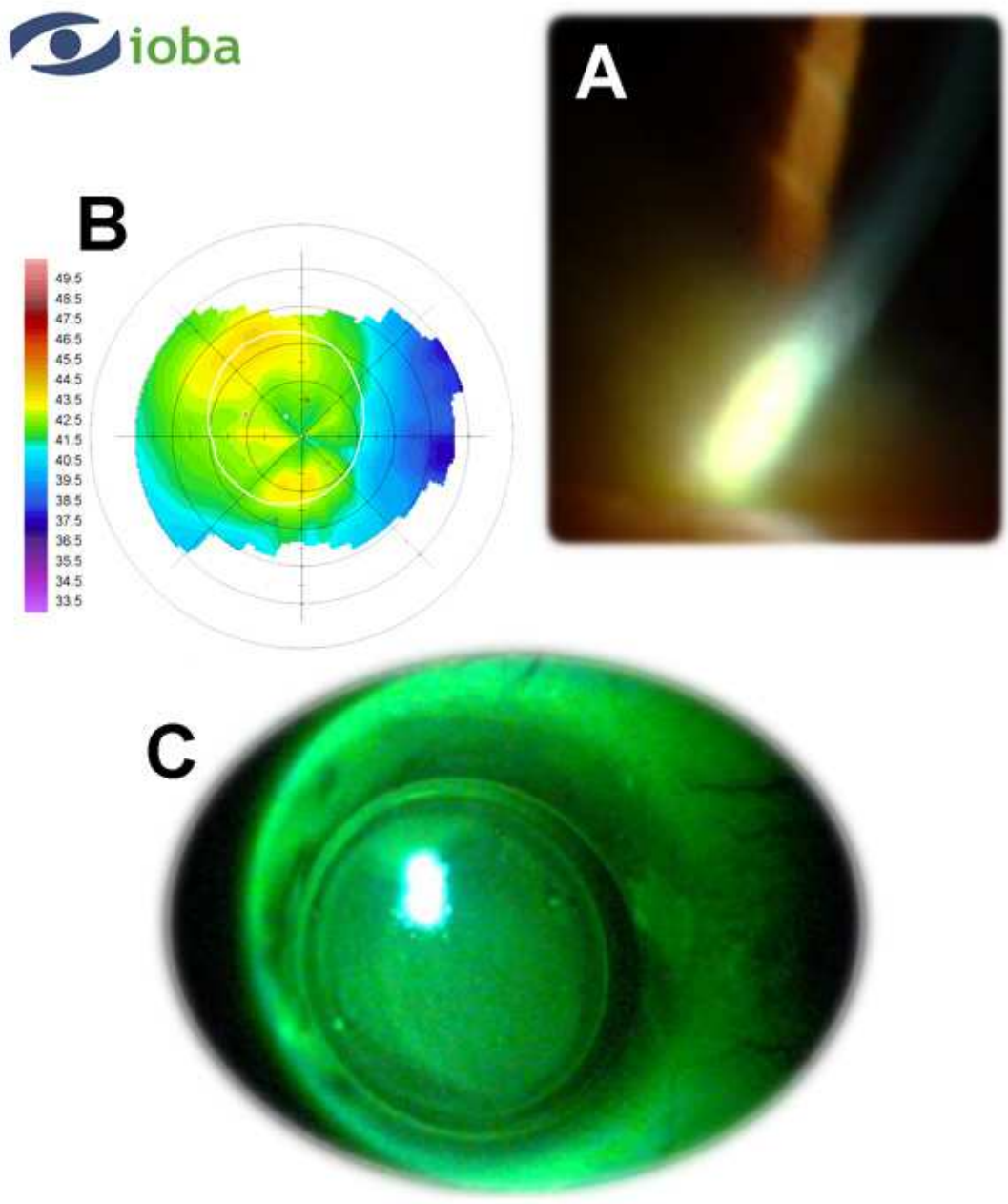

Fig. 8. Summary of Case 4. A. Slit lamp examination showed the neovascularization induced by low oxygen transmissibility of soft contact lens. B. Orbscan corneal topography with low irregular surface induced by contact lens corneal warpage. C. Fluorescein pattern with toric RGP lens shows the marks to assess the lens position.

between the contact lens and the cornea (Figure 8-C). The movement of the lens was correct, allowing appropriate lacrimal exchange. To obtain a stable position of the lens and to avoid any rotation with blinking, prism ballast had to be increased above the recommended value. In Figure 8-C, the stabilization marks can be seen, which indicates the horizontal meridian for this contact lens type, with a little rotation that was compensated for in the final power of the lens.

In conclusion, this case shows that in high ametropias and hypoxia-related ocular surface complications, RGP fitting permits correct management and an improvement in visual 
acuity. In the case of an internal astigmatism entirely, the design of the contact lens must be with an external toric surface, using the corresponding stabilization system to obtain a successful result.

\section{Irregular astigmatism correction with contact lenses}

Irregular astigmatism correction with RGP lenses allows for significant improvement in visual acuity as compared with standard spectacles correction (Martin R and Rodriguez G, 2005; Titiyal JS, 2006).

For this reason, RGP contact lens management is the first option in some corneal pathologies with irregular cornea, such as keratoconus (Rabinowitz Y, 1998). However, other pathologies, such as Herpex keratitis and other conditions, may produce irregular astigmatisms or irregular cornea. Cases are observed after surgical procedures (corneal keratoplastia, corneal refractive surgery complications and others) and corneal trauma.

\subsection{Irregular astigmatism after corneal disease}

Different corneal pathologies might induce irregular corneal surfaces. The pathologies include corneal dystrophies, such as keratoconus (Case 5) or pellucid marginal degeneration. Corneal infections might also induce permanent irregular corneal surfaces (Case 6).

We present two representative cases of irregular astigmatism after a surgical procedure: 1) a complicated LASIK surgery (Case 7) and 2) corneal keratoplasty (Case 8). A third case (Case 9) involves corneal trauma and describes its management with RGP contact lenses.

\subsubsection{Case 5: Keratoconus management with RGP contact lens}

A 27-year-old male patient was referred for contact lens fitting. The patient history revealed that the patient had been diagnosed with keratoconus in the right eye five years ago.

Visual acuity, refraction and keratometry are shown in Table 10. Slit lamp examination showed a corneal leucoma in the keratoconus apex with a decreasing corneal thickness (Figure 9-A).

\begin{tabular}{|c|c|c|c|c|}
\hline VA & $\begin{array}{c}\text { Subjective } \\
\text { refraction }\end{array}$ & DCVA & Manual keratometry & VA with CL \\
\hline Not taken & $-6.50-2.50 \times 60^{\circ}$ & 0.2 & $\begin{array}{c}\text { Not possible. Mires } \\
\text { distorted. }\end{array}$ & 0.6 \\
\hline
\end{tabular}

Table 10. Visual acuities before and after contact lens fitting and manual keratometry. VA: visual acuity, DCVA: Distance corrected visual acuity, CL: Contact Lens.

Corneal topography is not a requirement for fitting keratoconus patients, but it is certainly a good starting point. Corneal topography establishes the position of the cone apex and a basic shape pattern. Keratograph topography revealed an irregular cornea with an astigmatism of $6.80 \mathrm{D}$ approximately. A multicurve design for the keratoconus RGP contact lenses was proposed to improve the visual acuity (Hwang JS, 2010).

The lens parameters are shown in Table 11. The examination revealed good movement and tear exchange. The central area over the cone displayed central apical clearance in the keratoconus apex and a mild peripheral alignment with slightly optimal clearance under the peripheral curve. Although the edge lift is not ideal, tear exchange was present (Figure 9-C). 


\begin{tabular}{|c|c|c|c|c|c|}
\hline Radius & $\phi \mathbf{T}$ & Power & Design/ Model & Material & Manufacturer \\
\hline $5.80 \mathrm{~mm}$ & $8.80 \mathrm{~mm}$ & $-15.25 \mathrm{D}$ & $\begin{array}{c}\text { Multicurve/ } \\
\text { KAKC F }\end{array}$ & Boston EO & $\begin{array}{c}\text { Hecht Contactlinsen / } \\
\text { Conoptica }\end{array}$ \\
\hline
\end{tabular}

Table 11. Lens parameters. $\phi \mathrm{T}$ : Total diameter.

The management of keratoconus with RGP contact lenses is generally time-consuming. Specifically designed RGP contact lens with small diameters can be a good alternative in these cases to improve visual acuity.

\subsubsection{Case 6: Post-herpes keratitis irregular cornea}

We present the case of a 62-year-old male patient who was referred for contact lens fitting. The patient history revealed that the patient had been diagnosed with herpes zoster ophthalmicus (HZO) five years ago. Painful cutaneous lesions appeared on the right side of his face and are associated with severe ocular pain in the right eye.

Corneal scarring following HZO can cause significant vision loss (Catron T, 2008). Most of these patients require photorefractive keratectomy (Kaufman SC, 2008), keratoprosthesis (Todani A, 2009) or penetrating keratoplasty (Birnbaum F, 2010) for visual acuity recovery. RGP contact lens, which can mask significant amounts of irregular astigmatism, can improve visual acuity in some of these patients (Titiyal JS, 2006; Kanpolat A, 1995; Jupiter DG, 2000).

Visual acuity, refraction and keratometry are shown in Table 12. The patient had never worn spectacles or contact lenses. Slit lamp examination showed two corneal scars in the paracentral area, which affects the pupil axis (Figure 10-A). The scars caused an alteration in the corneal curvature along the vertical axis (Figure 10-C). The corneal topography revealed an irregular cornea with an astigmatism of $14 \mathrm{D}$.

\begin{tabular}{|c|c|c|c|c|}
\hline Visual acuity & Subjective refraction & DCVA & Manual keratometry & VA with CL \\
\hline 0.25 & $-4.00 \times 175^{\circ}$ & 0.6 & $\begin{array}{c}8.25 \mathrm{~mm} @ 180^{\circ} / \\
7.60 \mathrm{~mm} @ 90^{\circ}\end{array}$ & 1.0 \\
\hline
\end{tabular}

Table 12. Visual acuities before and after contact lens fitting, refraction and manual keratometry. VA: visual acuity, DCVA: Distance corrected visual acuity. CL: Contact Lens.

The fitting of contact lenses in a patient who has corneal scars caused by corneal diseases is generally difficult. In this case, these scars resulted in a high regular astigmatism, so it could be managed like a standard toric RGP contact lens fitting. After two diagnostic contact lenses in the same visit, the definitive contact lens was calculated.

The lens parameters are shown in Table 13. The examination revealed good centering and movement. The fluorescein patterns (Figure 10-E) showed good central alignment with two paracentral clearances in the two scars zones (vertical meridian), mild peripheral alignment with slightly optimal clearance under the peripheral curve and good edge clearance to facilitate tear exchange.

\begin{tabular}{|c|c|c|c|c|c|}
\hline Radius & $\phi \mathbf{T}$ & Power & Design/ Model & Material & Manufacturer \\
\hline $7.70 \mathrm{~mm}$ & $9.60 \mathrm{~mm}$ & $+1.50 \mathrm{D}$ & $\begin{array}{c}\text { Bitoric/BIAS } \\
\text { MAC }\end{array}$ & Boston ES & $\begin{array}{c}\text { Hecht Contactlinsen / } \\
\text { Conoptica }\end{array}$ \\
\hline
\end{tabular}

Table 13. Contact lens parameters. $\phi \mathrm{T}$ : Total diameter. 


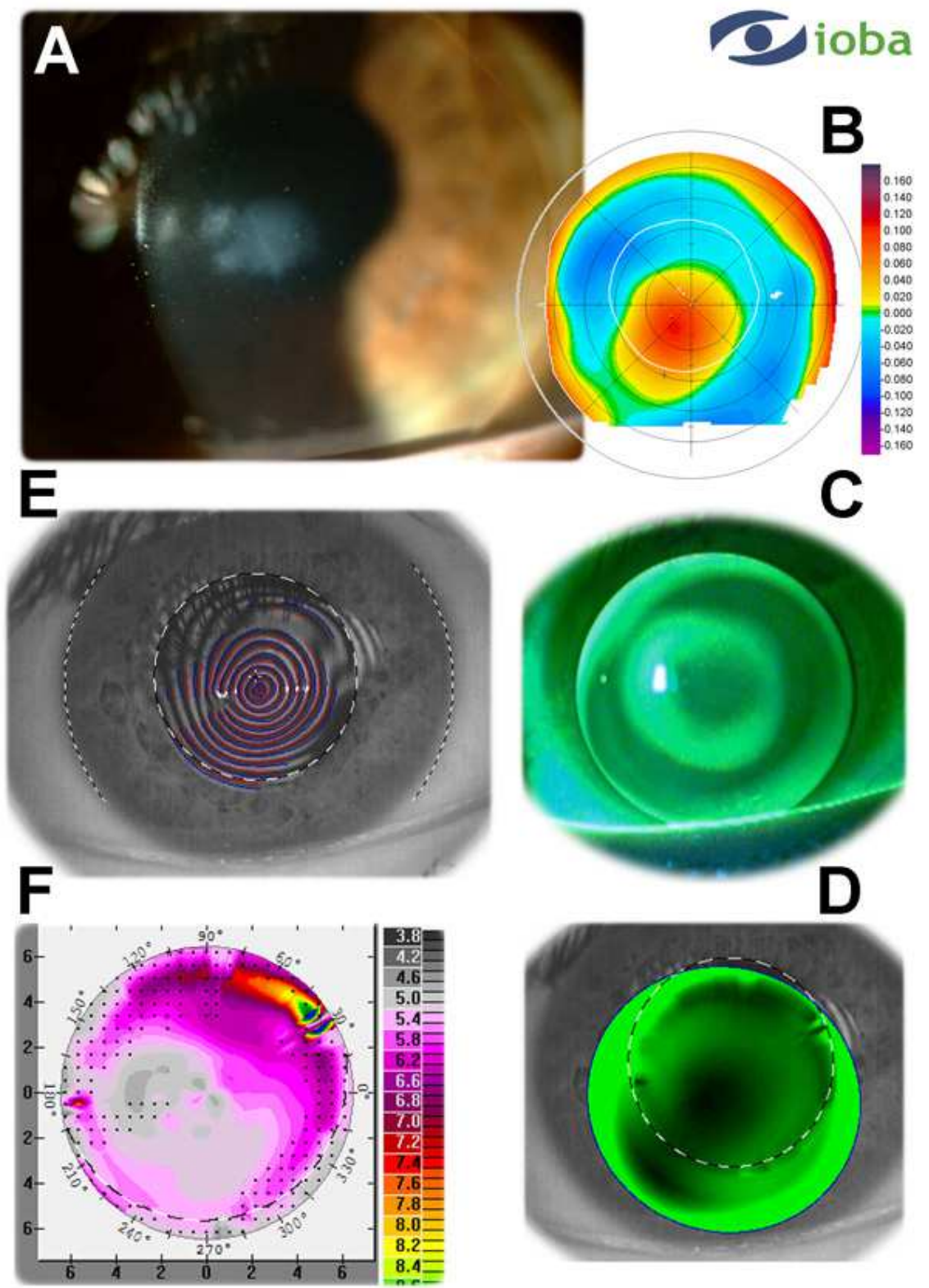

Fig. 9. Summary of Case 5. A. Slit lamp examination showed corneal leucoma in the central area that affects the pupil axis. B. Orbscan elevation topography (anterior elevation is the best fitting surface). C. Fluorescein pattern with multicurve RGP lens. D. Keratograph simulated fluorescein pattern. The software permits the positioning of contact lens like the real fitting. E. Distorted image with the Placido disc. F.- Keratograph topography. 

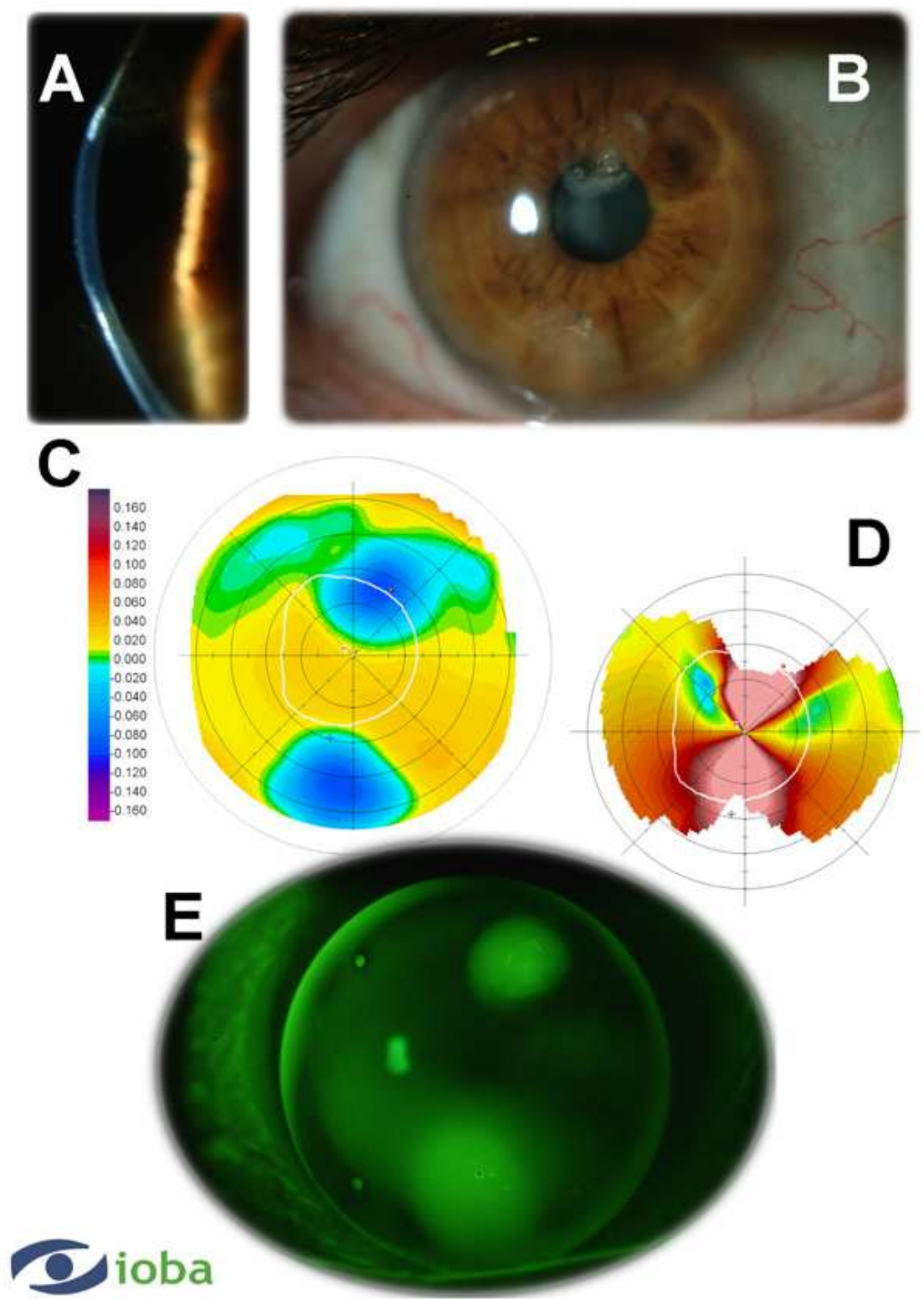

Fig. 10. Summary of Case 6. A. Slit lamp examination (optical section) that showed two corneal scars along the vertical axis. B. One of the scars affected the pupil axis. C. Orbscan elevation topography showed an irregular corneal surface with high astigmatism (anterior elevation best fitting surface). D. Orbscan keratometric map, which shows a high astigmatism with a fairly regular pattern. E. Fluorescein pattern with toric RGP lens showed central alignment and two apical clearances in the scar zone. 


\subsection{Irregular astigmatism after surgical procedure}

Irregular astigmatism can be found after different surgical procedures, especially in corneal procedures, such as refractive surgery or corneal keratoplasty. In corneal refractive surgery with an excimer laser, irregular corneal surfaces can be found due to different reasons, such as corneal wound healing, corneal keratitis, irregular laser ablation, decentered surgery and others. In corneal keratoplasty, the irregular surface is related to the donor button position and stitch pressure.

In these cases, surgical management could be non-indicated, and RGP contact lens fitting could be a good option for visual acuity improvement. We present two different cases fitted with RGP after decentered LASIK and successful corneal keratoplasty.

\subsubsection{Case 7: Irregular cornea post Refractive Surgery LASIK}

Male, 37-years old, underwent LASIK ten years ago. The previous refraction was $-11.00 \mathrm{D}$ in both eyes. Currently, the patient presents myopic regression and has bad vision when it is corrected with ophthalmic lenses (Table 14). Corneal topography (Figure 11-A) shows the decentered myopic ablation pattern that is responsible for the reduced quality of vision.

\begin{tabular}{|c|c|c|c|c|}
\hline VA & Subjective refraction & DCVA & Manual keratometry & VA with CL \\
\hline 0.16 & -5.00 & 0.7 & $\begin{array}{c}9.45 \mathrm{~mm} @ 95^{\circ} / \\
9.30 \mathrm{~mm} \mathrm{@} \mathrm{5}\end{array}$ & 0.8 \\
\hline
\end{tabular}

Table 14. Visual acuities before and after contact lens fitting and manual keratometry. VA: visual acuity, DCVA: Distance corrected visual acuity, CL: Contact Lens.

Surgical correction was not possible because of the reduced corneal thickness (Figure 11-D); therefore, RGP lens fitting was indicated with the aim to obtain a regular optical surface. Because the cornea presents an oblate shape (flatter centrally than peripherally), a reverse geometry design was selected to achieve parallelism between the contact lens and the cornea (Figure 11-C).

Table 15 shows the parameters of the final lens. The back optic zone radius of the lens was selected to provide corneal alignment between the first peripheral curve and the peripheral cornea to reduce central pooling in the refractive ablation zone and to have an optimal intermediate fit with a poorly defined contact and slightly wide edge clearance (Martin and Rodriguez, 2005). The fluorescein pattern (Figure 11-C) showed moderate pooling at the central ablated area and a mid-peripheral alignment with slightly optimal clearance under the peripheral curve of the contact lens. Although vision acuity with the contact lens was very similar to that obtained with spectacles, the patient reported significant vision improvement.

In this case, a reverse geometry RGP contact lens fitting was effective to correct surgically induced irregular surfaces with improved patient vision and comfortable wear.

\begin{tabular}{|c|c|c|c|c|c|}
\hline Radius & $\phi \mathbf{T}$ & Power & Design/ Model & Material & Manufacturer \\
\hline $9.15 \mathrm{~mm}$ & $10.60 \mathrm{~mm}$ & $-9.00 \mathrm{D}$ & Ortokon & Boston ES & $\begin{array}{c}\text { Hecht Contactlinsen } \\
\text { / Conoptica }\end{array}$ \\
\hline
\end{tabular}

Table 15. The lens parameters. $\phi \mathrm{T}$ : Total diameter. The peripheral code was 4.0 diopter steeper than the base radius. 


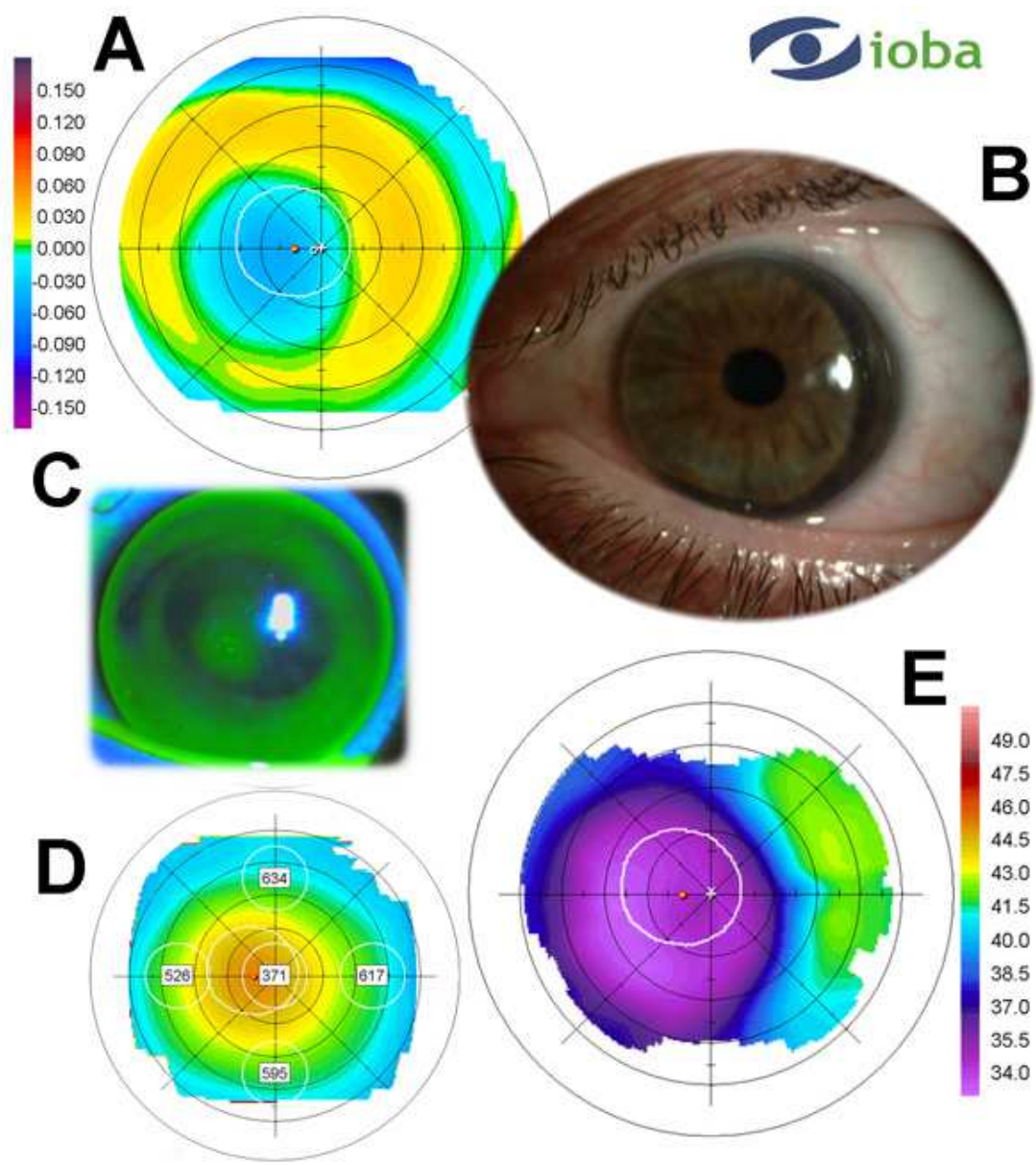

Fig. 11. A summary of Case 7. A. Orbscan elevation topography showed the decentered ablation of the excimer laser. B. Contact lens position with optimum centering. C. Fluorescein pattern of the contact lens. D. The Orbscan pachymetric map showed central thinning of the cornea. E. Corneal topography revealed the effect of the myopic excimer laser ablation.

\subsubsection{Case 8: Post-penetrating keratoplasty irregular cornea}

A 25-year-old male with history of a bilateral keratoconus and a good tolerance of RGP contact lenses had corneal hydrops in the left eye. Penetrating keratoplasty was required to restore corneal transparency (Figure 12-A). Corneal transplant was successfully performed. After surgery many stitches were removed, but at the time of discharge, some stitches have remained (Figure 12-B) and were responsible for 9 diopters of corneal astigmatism (Figure 12-C). With subjective refraction, the patient obtained good visual acuity (Table 16). Due to high astigmatic aniseikonia induced with spectacles, the correction was made using contact lenses. 


\begin{tabular}{|c|c|c|c|c|}
\hline Visual acuity & Subjective refraction & DCVA & Manual keratometry & VA with CL \\
\hline 0.16 & $+1.00-9.00 \times 80^{\circ}$ & 1.0 & $\begin{array}{c}8.30 \mathrm{~mm} @ 85^{\circ} / \\
6.60 \mathrm{~mm} @ 175^{\circ}\end{array}$ & 1.5 \\
\hline
\end{tabular}

Table 16. Visual acuities before and after contact lens fitting, refraction and manual keratometry. VA: visual acuity, DCVA: Distance corrected visual acuity. CL: Contact Lens.

The astigmatism present in this patient was fully corneal but had an irregular component due to the surgery. For this reason, RGP contact lenses were selected instead of soft contact lenses. Lenses with toric back surface were selected to obtain parallelism with the cornea and a stable fitting. This lens type presents two different powers, one in each principal meridian. This design allows for the correction of corneal astigmatism that matches up with a refractive astigmatism. An induced astigmatism is caused by the large difference between the internal radius and the refractive index of the lens material. The neutralization of the induced astigmatism requires a toroidal front surface, so a bitoric lens is needed. The final refractive effect is spherical, and this type is called a compensated bitoric lens: the back toric surface corrects the entire refractive cylinder created due to the corneal toricity and the front surface incorporates the correction for the induced astigmatism (Efron, 2002).

Table 17 shows the final parameters of the lens. The base curves were selected in agreement with the nomogram provided by the manufacturer on the basis of manual keratometry and corneal topography. Figure 12-D showed the fitting fluorogram, which shows the general parallelism between the cornea and contact lens with slightly irregular areas and without excessive contact. The lens movement was correct, allowing adequate tear exchange, and the lens position was stable. The stabilization marks (which in this contact lens type indicates the flattest meridian of the lens) match up with flattest meridian of the cornea. The lens provided excellent visual acuity with good subjective tolerance.

\begin{tabular}{|c|c|c|c|c|c|}
\hline Radius & $\phi \mathbf{T}$ & Power & Design/ Model & Material & Manufacturer \\
\hline $\begin{array}{c}7.90 \mathrm{~mm} / \\
7.20 \mathrm{~mm}\end{array}$ & $8.70 \mathrm{~mm}$ & $-2.00 \mathrm{D}$ & KAKC-N BTC & Boston ES & $\begin{array}{c}\text { Hecht Contactlinsen } \\
\text { / Conoptica }\end{array}$ \\
\hline
\end{tabular}

Table 17. Contact lens parameters. $\phi \mathrm{T}$ : Total diameter.

\subsection{Irregular astigmatism after corneal trauma}

A 38-year-old male patient was referred for contact lens fitting. The patient had undergone vitrectomy (retinal detachment) and lens extraction after open globe injuries due to a work accident in right eye (RE) one year ago. Corneal perforation injuries can cause corneal scars and irregular astigmatisms (McMahon TT, 1997). Most of these patients require penetrating keratoplasty for visual acuity recovery. However, different types of RGP contact lens have been proposed for improved visual acuity in impaired post-traumatic scarred corneas (Grunauer-Kloevekorn C, et al 2004; Boghani S, et al 1991; Kok JH, et al, 1991).

The visual acuity, refraction and keratometry are shown in Table 18. The patient had never worn spectacles or contact lenses. Slit lamp examination showed an inferior conjunctival scar secondary to eye surgery and a corneal scar in the central area that affects the pupil axis (Figure 13-A). The pupil was inferior and nasal decentered. Orbscan II topography revealed an irregular cornea with an astigmatism of 9.50 D. 


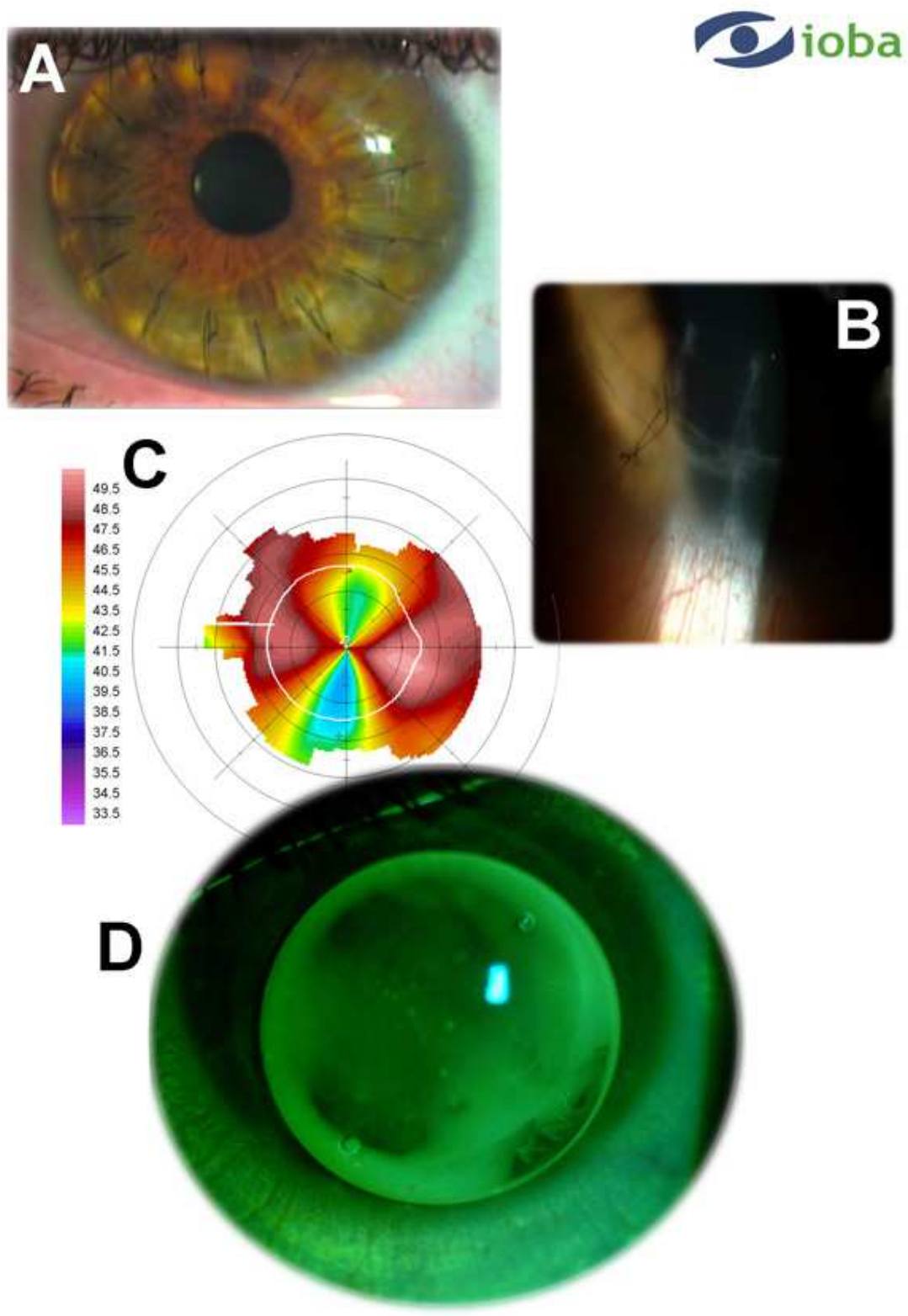

Fig. 12. A summary of Case 8. A. Slit lamp examination showed the penetrating keratoplasty. B. Detail of the deeper stitch. C. Orbscan corneal topography with $9 \mathrm{D}$ of a slightly regular astigmatism in the center of the cornea. D. Fluorescein pattern with toric RGP lens showed central alignment. 


\begin{tabular}{|c|c|c|c|c|}
\hline VA & $\begin{array}{c}\text { Subjective } \\
\text { refraction }\end{array}$ & DCVA & Manual keratometry & $\begin{array}{c}\text { VA with } \\
\text { CL }\end{array}$ \\
\hline $\begin{array}{c}\text { Counter } \\
\text { finger at } 1 \mathrm{~m}\end{array}$ & Not taken & $\begin{array}{c}\text { Not } \\
\text { taken }\end{array}$ & $\begin{array}{c}7.45 \mathrm{~mm} @ 60^{\circ} / 7.50 \mathrm{~mm} @ 150^{\circ} . \\
\text { Mires were grossly distorted. }\end{array}$ & 0.8 \\
\hline
\end{tabular}

Table 18. Visual acuities before and after contact lens fitting and manual keratometry. VA: visual acuity, DCVA: Distance corrected visual acuity CL: Contact Lens.

Reverse-geometry RGP contact lenses were proposed to improve visual acuity. An empirical fitting was provided. After three diagnostic contact lenses in two visits, the definitive contact lens was calculated. The lens parameters are shown in Table 19. Examination revealed good centering and movement.

The fluorescein patterns (Figure 13-D) showed central pooling with a small apical clearance in the scar zone, mild peripheral alignment with slightly optimal clearance under the peripheral curve and good even edge clearance to facilitate tear exchange.

\begin{tabular}{|c|c|c|c|c|c|}
\hline Radius* & $\phi \mathbf{T}$ & Power & Design/ Model & Material & Manufacturer \\
\hline $\begin{array}{c}8.20 \mathrm{~mm} \\
\text { FPC } 7.60 \mathrm{~mm}\end{array}$ & $10.20 \mathrm{~mm}$ & $+11.25 \mathrm{D}$ & $\begin{array}{c}\text { ATD / Reverse } \\
\text { geometry }\end{array}$ & Boston XO & $\begin{array}{c}\text { Hecht Contactlinsen } \\
\text { / Conoptica }\end{array}$ \\
\hline
\end{tabular}

Table 19. The lens parameters. $\varphi$ T: Total diameter. ATD: Anterior tangential design. * The first peripheral curve (FPC) was $7.60 \mathrm{~mm}$ (this radius is steeper than the central radius of the optical zone because we used a reverse-geometry contact lens).

The fitting of contact lenses in a patient who has corneal scars caused by perforating corneal injuries is difficult. RGP reverse-geometry contact lens fitting with large diameters can be a good alternative in these cases. This fitting could take less time and require fewer visits than standard or aspheric RGP contact lenses in these patients. Computer-aided fitting was of limited value in cases with irregular corneal surfaces.

\section{Conclusions}

Contact lens management of patients with astigmatisms could be an option to improve the visual acuity obtained with spectacles, especially in cases of irregular astigmatisms.

Regular astigmatisms could be corrected with soft or RGP toric contact lenses, but irregular astigmatism is better corrected with RGP lenses adapted to the corneal topography. The effect of the tear lens in patients with an astigmatism fitted with an RGP lens permits optimal correction of the regular and irregular astigmatism and an improvement of the visual acuity.

Astigmatic patient management must include contact lens fitting as a treatment option along with spectacles and refractive procedures.

\section{Acknowledgment}

The authors acknowledge Hecht Contactlinsen / Conoptica for the collaboration to facilitate Figure 3. The authors do not have any conflicts of interest or commercial relationships with any device or product included in this chapter. 


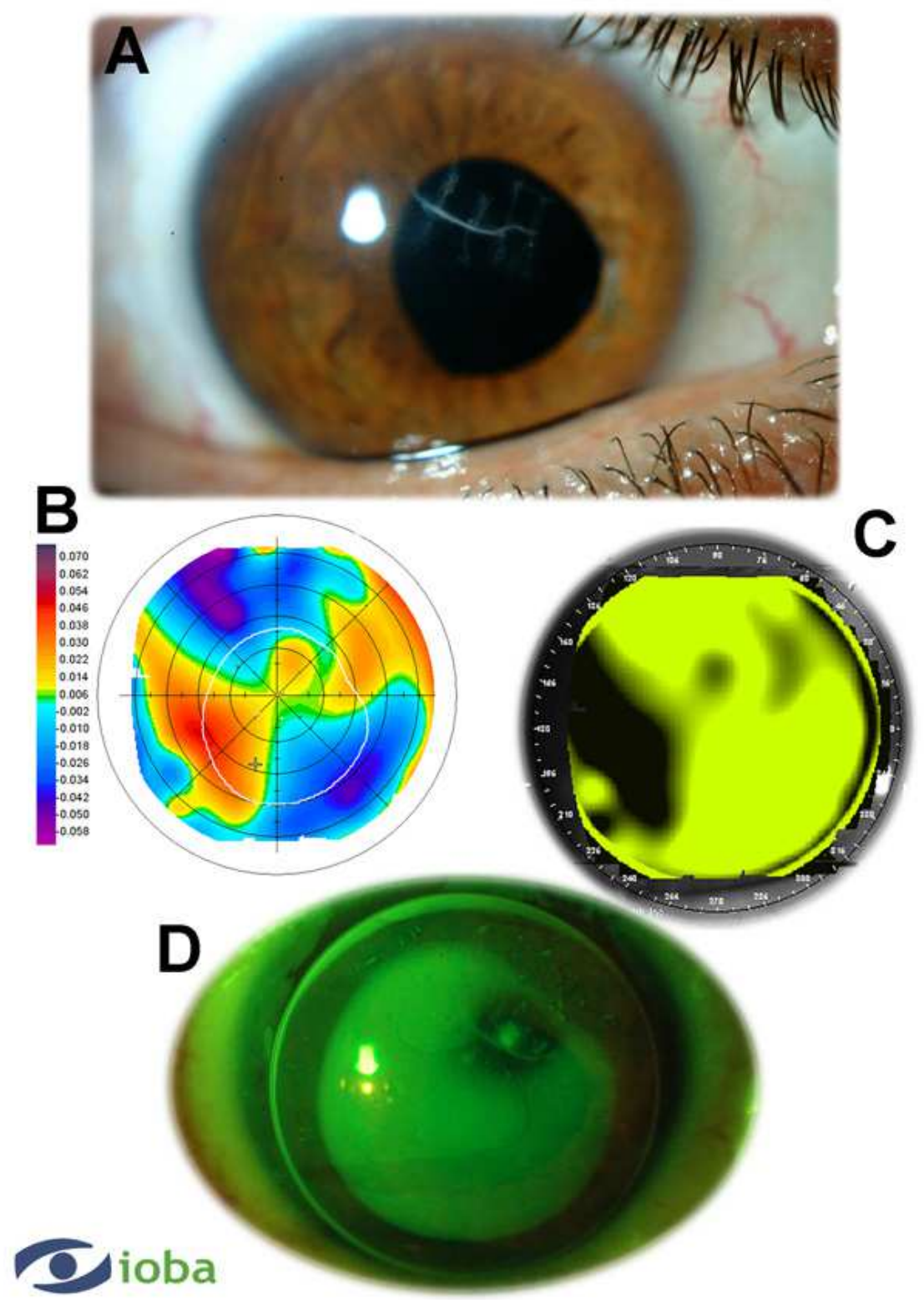

Fig. 13. A summary of Case 9. A. Slit lamp examination showed corneal scarring in the central area that affect the pupil axis. B. Orbscan elevation topography showed an irregular corneal surface with high astigmatism (the anterior elevation had the best fitting surface). C. Orbscan-simulated fluorescein pattern of $10.20 \mathrm{~mm}$ diameter RGP lens with a back posterior radius of $8.20 \mathrm{~mm}$. Several differences with the real fluorescein pattern are shown. D. Fluorescein pattern with reverse-geometry and large-diameter RGP lens. 


\section{References}

American Academy Ophthalmology (2005). Basic and Clinical Sciences Course: Clinical optics. American Academy Ophthalmology, San Francisco, Californa (USA).

American Heritage Dictionary (2011). Available from : www.houghtonmifflinbooks.com

Benjamin W (1998). Boris's Clinical refraction, WB Saunders Company, ISBN 7216-5688-9, Philadelphia, Pennsylvania (USA).

Birnbaum F, Reinhard T (2010). Penetrating keratoplasty in corneal infections with herpes simplex virus and varicella zoster virus. Lin Monbl Augenheilkd. 227:400-6.

Boghani S, Cohen EJ, Jones-Marioneaux S. (1991). Contact lenses after corneal lacerations. CLAO 17:155-8.

Catron T, Hern HG (2008). Herpes zoster ophthalmicus. West J Emerg Med. 9:174-6.

Efron N (2002). Contact lens practice. Butterworth-Heinemann. Oxford, ISBN 7506-4690-X, United Kingdom.

Efron N (2004). Contact lens complications. Butterworth-Heinemann. Oxford, ISBN 0750655348, 9780750655347. United Kingdom.

Grunauer-Kloevekorn C, Habermann A, Wilhelm F, et al (2004). Contact lens fitting as a possibility for visual rehabilitation in patients after open globe injuries. Klin Monatsbl Augenheilkd 221:652-7.

Hom M (2006). Manual of contact lens prescribing and fitting with CD-Rom, ButterworthHeinemann, ISBN 7506-7517-9, Woburn, MA (USA).

Hwang JS, Lee JH, Wee WR, Kim MK (2010). Effects of multicurve RGP contact lens use on topographic changes in keratoconus. Korean J Ophthalmol. 24:201-6.

Ichijima H, Cavanagh HD (2007). How Rigid Gas-Permeable lenses supply more oxygen to the cornea than silicone hydroges: a nex model. Eye \& Contact Lens 33(5): 216-223.

Jupiter DG, Katz HR (2000). Management of irregular astigmatism with rigid gas permeable contact lenses. CLAO 26:14-7.

Kanpolat A, Ciftci OU (1995). The use of rigid gas permeable contact lenses in scarred corneas. CLAO 21:64-6.

Kaufman SC, 2008. Use of photorefractive keratectomy in a patient with a corneal scar secondary to herpes zoster ophthalmicus. Ophthalmology. 115:S33-4.

Key JE (1998). The CLAO Pocket Guide to Contact Lens Fitting. 2nd ed. CLAO Publications, New Orleans, USA.

Kok JH, Smulders F, van Mil C. (1991). Fitting of aspheric high gas-permeable rigid contact lenses to scarred corneas. Am J Ophthalmol 112:191-4.

Martin R, Rodriguez G (2005). Reverse geometry contact lens fitting after corneal refractive surgery. J Refract Surg 21:753:756.

McMahon TT, Devulapally J, Rosheim KM, et al (1997). Contact lens use after corneal trauma. J Am Optom Assoc 68:215-24.

Meyler JG, Ruston DM (1994). Rigid Gas Permeable aspheric back surface contact lenses- a review. Optician 208:5467:22-30.

Michaels D (1988). Basic refraction techniques. Raven Press, ISBN 88167-471-0, New York, USA.

Rabinowitz Y (1998). Keratoconus. Surv Ophthalmol 42:297-319.

Titiyal JS, Sinha R, Sharma N, et al (2006). Contact lens rehabilitation following repaired corneal perforations. BMC Ophthalmology 6:11-4.

Todani A, Gupta P, Colby K (2009). Type I Boston keratoprosthesis with cataract extraction and intraocular lens placement for visual rehabilitation of herpes zoster ophthalmicus: the "KPro Triple". Br J Ophthalmol. 93:119.

Young G (2003). Toric contact lens designs in hyper-oxygen materials. Eye Contact Lens 29:S171-3 


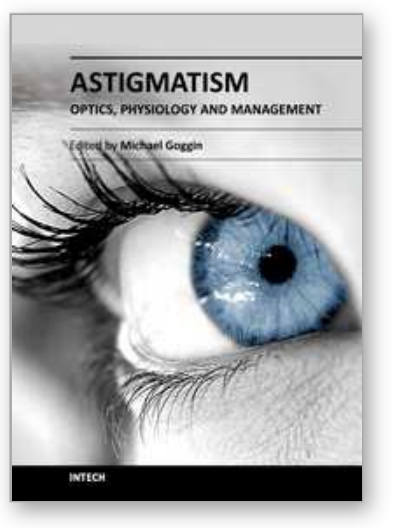

\author{
Astigmatism - Optics, Physiology and Management \\ Edited by Dr. Michael Goggin
}

ISBN 978-953-51-0230-4

Hard cover, 308 pages

Publisher InTech

Published online 29, February, 2012

Published in print edition February, 2012

This book explores the development, optics and physiology of astigmatism and places this knowledge in the context of modern management of this aspect of refractive error. It is written by, and aimed at, the astigmatism practitioner to assist in understanding astigmatism and its amelioration by optical and surgical techniques. It also addresses the integration of astigmatism management into the surgical approach to cataract and corneal disease including corneal transplantation.

\title{
How to reference
}

In order to correctly reference this scholarly work, feel free to copy and paste the following:

Raul Martín Herranz, Guadalupe Rodríguez Zarzuelo and Victoria de Juan Herráez (2012). Contact Lens Correction of Regular and Irregular Astigmatism, Astigmatism - Optics, Physiology and Management, Dr. Michael Goggin (Ed.), ISBN: 978-953-51-0230-4, InTech, Available from:

http://www.intechopen.com/books/astigmatism-optics-physiology-and-management/contact-lens-correction-ofregular-and-irregular-astigmatism

\section{INTECH}

open science | open minds

\section{InTech Europe}

University Campus STeP Ri

Slavka Krautzeka 83/A

51000 Rijeka, Croatia

Phone: +385 (51) 770447

Fax: +385 (51) 686166

www.intechopen.com

\section{InTech China}

Unit 405, Office Block, Hotel Equatorial Shanghai

No.65, Yan An Road (West), Shanghai, 200040, China

中国上海市延安西路65号上海国际贵都大饭店办公楼 405 单元

Phone: +86-21-62489820

Fax: $+86-21-62489821$ 
(C) 2012 The Author(s). Licensee IntechOpen. This is an open access article distributed under the terms of the Creative Commons Attribution 3.0 License, which permits unrestricted use, distribution, and reproduction in any medium, provided the original work is properly cited. 